\title{
La importancia de las capacidades dinámicas en el replanteamiento de una ventaja competitiva innovadora. Estudio de caso en empresas tecnológicas cordobesas
}

\section{The importance of dynamic capabilities in the reformulation of an innovative competitive advantage. Case study of Cordoba technology companies}

\author{
María Amalia Trillo-Holgado \\ maru.trillo@uco.es@0000-0002-1626-8066 \\ Carolina León-Urban \\ d22leurc@uco.es@0000-0002-3862-6784 \\ Rocío López-Caballero \\ d22locar@uco.es@0000-0003-2701-9951
}

Universidad de Córdoba (Área de Organización de Empresas). Edificio Gregor Mendel (C5), $3^{a}$ planta. Campus de Rabanales. Ctra. Madrid-Cádiz, Km. 369. 14071 Córdoba, España

\section{INFO ARTÍCULO}

Recibido: 08/10/2021

Revisado: 05/01/2022

Aceptado: 13/01/2022

\section{PALABRAS CLAVE}

Ventaja competitiva Capacidades dinámicas Innovación

Estudio de caso

\section{KEYWORDS}

Competitive advantage

Dynamic capabilities

Innovation

Case study

\begin{abstract}
RESUMEN
La capacidad de innovación de las empresas se relaciona con la reconfiguración o modificación de sus ventajas competitivas. Su mejor explicación atiende a la perspectiva de las capacidades dinámicas (habilidades organizativas para gestionar sus recursos en entornos cambiantes), campo que requiere de profundización práctica. Metodológicamente se construye un modelo a través del cual se identifican determinadas variables e indicadores para facilitar a los directivos explicar cómo aquellos recursos y capacidades que intervienen en mayor medida en el desarrollo de nuevos procesos, productos o servicios se relacionan la reconfiguración de la ventaja competitiva de la empresa. Para corroborar la utilidad del modelo se lleva a cabo un estudio de caso ejemplar dentro del sector tecnológico basado en una empresa pública y otra privada. Como conclusiones y resultados, se puede afirmar que se apoya la literatura reciente verificando cómo las actividades específicas de innovación respaldan las capacidades dinámicas a partir de las que se determina la ventaja competitiva sostenible de la empresa. La cultura y el comportamiento colaborativo juegan un papel fundamental que, junto a la tecnología resulta especialmente evidente en el caso del sector privado en comparación con el público.
\end{abstract}

\begin{abstract}
The innovation capacity of companies is related to the reconfiguration or modification of their competitive advantages. It is best explained from the perspective of dynamic capabilities (organisational abilities to manage their resources in changing environments), a field that requires further practical study. Methodologically, a model is provided. The model identifies the most important variables and indicators in order to facilitate managers strategy. That model allows them to explain how those resources and capacities taking part in the development of new processes, products or services influence the reconfiguration of competitive advantage. To support the utility of the model, an exemplary case carried out within the technology sector based on a public and a private company. As conclusions and results, it can be stated that this empirical study supports the scientific literature, verifying how specific innovation activities have to do with the dynamic capabilities from which the company's sustainable competitive advantage is determined. Regarding that, culture and collaborative behavior play a fundamental role, which along with technology, are evident in the case of the private sector compared to the public one.
\end{abstract}




\section{INTRODUCCIÓN}

En los últimos años, se ha considerado que la capacidad de innovación de las empresas influye en el logro y mantenimiento de sus ventajas competitivas, las cuales les van a permitir tener un mejor desempeño que el de sus competidores y situarlas en una posición superior para competir. En este sentido, Piening y Salge (2015) señalan la necesidad investigadora de profundizar en los antecedentes, contingencias y consecuencias del proceso de innovación empresarial, tanto desde el punto de vista teórico como práctico.

Por el motivo referido más arriba, este trabajo pretende explicar cómo se reconfigura la ventaja competitiva a través de la capacidad de innovación de las empresas mediante la perspectiva de las capacidades dinámicas, la cual se basa en la habilidad de las organizaciones para renovar sus competencias y dar una respuesta rápida a los cambios del entorno (Miranda, 2015) a través de la búsqueda de oportunidades, con el fin de crear nuevos productos, servicios o procesos. No en vano, Teece (2014) señaló el impacto significativo de la teoría de las capacidades dinámicas sobre sobre la gestión estratégica, habida cuenta de que, a este respecto, la literatura no está claramente unificada. Así mismo, Mamédio et al. (2019) resaltan el interés de ahondar en el tiempo que necesitan las diferentes capacidades a la hora de materializarse en resultados medibles según las distintas industrias a las que se refieran.

Intentando dar respuesta a la problemática expuesta, el trabajo consta de una parte teórica en la que se analizan los principales factores causantes del dinamismo del entorno y cómo las capacidades dinámicas y los recursos estratégicos influyen en el proceso de innovación empresarial con el ánimo de contribuir a la sistematización del conocimiento al respecto. En segundo lugar, se construye un modelo conceptual en el que se muestra la innovación como resultado de las capacidades dinámicas y fuente de la ventaja competitiva de las organizaciones y, por último, a partir de dicho modelo, se verifican empíricamente los conocimientos previamente ordenados llevando a cabo un estudio de casos de dos empresas representativas en su ámbito geográfico, una del sector público y otra del privado, que actúan en el ámbito tecnológico. La elaboración de una entrevista semi-estructurada permite recabar la información objeto de análisis y explicar cómo se produce la reconfiguración de la ventaja competitiva a partir de la innovación desde la perspectiva de las capacidades dinámicas.

\section{MARCO TEÓRICO}

\subsection{El dinamismo del entorno}

Las empresas operan en entornos dinámicos, por lo que es importante prever los cambios que se puedan producir a fin de aprovechar las oportunidades brindadas por el mercado.

Suárez y Oliva (2005) definen el entorno de una organización como "el patrón de todas las condiciones e influencias externas que afectan a su vida y desarrollo", y el dinamismo como "la incertidumbre o inestabilidad (volatilidad) de un entorno". De forma similar, otros autores se refieren al dinamismo del entorno como la ratio de cambio e inestabilidad, así como al grado en el que el estado futuro del entorno resulta imprevisible.

Sin embargo, cabe considerar que el hecho de que se produzcan variaciones en un entorno competitivo no es condición suficiente para considerarlo de carácter dinámico. “En entornos estables también se producen cambios externos, pero estos cambios son, en gran medida, predecibles e incrementales" (Ambrosini et al., 2009), por lo que el concepto de dinamismo se centra en los cambios que resultan difíciles de predecir y que aumentan la incertidumbre. Así, el nivel de dinamismo depende de la regularidad, profundidad e incertidumbre asociadas a los cambios que surgen en el entorno competitivo de la empresa (Sidhu et al., 2007) que se ve obligada a establecer relaciones con otras empresas (Peng \& Beamish, 2014).

Se han clasificado los factores causantes del dinamismo en el entorno, dispersos en la literatura que habla de ellos, en tres grandes bloques: factores de oferta, factores de demanda y factores relativos al entorno macroeconómico (tabla 1). 
Tabla 1. Principales factores causantes del dinamismo en el entorno empresarial.

\begin{tabular}{|c|c|}
\hline Factores de Oferta & Posibles Causas de Dinamismo \\
\hline Materias primas & $\begin{array}{l}\text { Cambios bruscos en la disponibilidad y el precio de las } \\
\text { materias primas }\end{array}$ \\
\hline Tecnología & $\begin{array}{l}\text { Rápido progreso de nuevas tecnologías y procesos } \\
\text { productivos } \\
\text { Rápido avance en el desarrollo de nuevos productos }\end{array}$ \\
\hline Nuevos competidores & $\begin{array}{l}\text { Nacimiento de nuevas empresas } \\
\text { Entrada de nuevos competidores procedentes de otra } \\
\text { industria o área geográficas }\end{array}$ \\
\hline Factores de Demanda & Posibles Causas de Dinamismo \\
\hline Consumidores & $\begin{array}{l}\text { Cambios en los patrones de demanda, necesidades y } \\
\text { preferencias de los consumidores } \\
\text { Aparición de nuevos segmentos de mercado }\end{array}$ \\
\hline Otros factores macroeconómicos & Posibles Causas de Dinamismo \\
\hline Política gubernamental & $\begin{array}{l}\text { Cambios en la política económica, fiscal y financiera } \\
\text { Cambios en la regulación específica del sector }\end{array}$ \\
\hline Turbulencias económicas & $\begin{array}{l}\text { Cambios de ciclo económico } \\
\text { Sacudidas económicas }\end{array}$ \\
\hline
\end{tabular}

Fuente: Elaboración propia.

Desde el lado de la oferta, las fluctuaciones inesperadas en los precios de las materias primas desestabilizan la estructura de costes de las empresas que se ven obligadas a incrementar sus precios, lo que, dependiendo de la elasticidad-precio de la demanda, puede repercutir negativamente en el consumo de los productos. Además, el incremento en el precio de las materias primas puede hacer viable la utilización de otros insumos o métodos de producción que no resultaban rentables hasta el momento.

Otro de los factores de la oferta es el rápido avance de la tecnología. En los últimos años, el sector tecnológico ha experimentado profundos cambios dando lugar a múltiples innovaciones radicales, es decir, nuevos productos o procesos completamente diferentes a los ya existentes. Cuando estas innovaciones se producen con relativa frecuencia, el entorno se define como tecnológicamente dinámico. El dinamismo tecnológico puede darse en procesos productivos mediante el desarrollo o aplicación de nuevas tecnologías que permitan producir incurriendo en menores costes o aumentando el nivel de calidad de los productos, así como ofreciendo productos novedosos que satisfagan mejor las necesidades de los consumidores. Además, las capacidades analíticas relacionadas con el big data tienen un impacto muy positivo sobre las capacidades dinámicas potenciando la innovación incremental (Mikalef et al., 2019).

Por último, dentro de los factores de la oferta, se observa la amenaza de nuevos competidores, ya sea por el nacimiento de nuevas empresas o por la entrada de empresas procedentes de otras industrias o áreas geográficas. Una de las consecuencias del proceso de globalización es la intensificación de la competencia debido a la eliminación de barreras para la libre circulación de bienes y servicios, lo que ha favorecido el auge de empresas multinacionales que pasan a competir en un número creciente de países. Además, las economías nacionales están más interrelacionadas, produciéndose un mayor movimiento de capitales, de financiación y de tecnología entre ellas.

El segundo bloque, factores de la demanda, atiende a los consumidores. En la medida en que se produzcan cambios más o menos continuos e impredecibles en sus necesidades, aumentará el nivel de dinamismo en el entorno competitivo. Dentro de este dinamismo que afecta a los clientes, se encuentran los cambios en las preferencias y pautas de demanda de los consumidores actuales, así como la posibilidad de que aparezcan nuevos segmentos de clientes con nuevas necesidades. Las alteraciones de los patrones de compra de 
los clientes no sólo responden a los cambios en su nivel de ingresos o en los precios de los bienes y servicios, sino que también vienen motivadas por sus deseos.

El tercer y último conjunto de factores se refiere al entorno macroeconómico, cuya variación, dependiendo del grado y la frecuencia, puede generar incertidumbre e inestabilidad en el entorno competitivo de la empresa. Dichos factores hacen referencia a elementos de la política gubernamental y a variaciones que afectan a la economía en general. La política económica, fiscal y financiera varía en función del partido político que gobierne en cada momento, por lo que no se mantienen estables dado los continuos cambios de gobierno que se producen, lo cual genera una situación de incertidumbre para los agentes económicos y alteran las reglas del juego competitivo (Kale, 2010). Por otra parte, los cambios de ciclo económico (de expansión a recesión, y viceversa) y las sacudidas económicas (subida repentina de tipos de interés) alteran el marco general en el que se desarrolla la competencia (Suárez \& Oliva, 2005). También podríamos incluir las políticas supranacionales.

En este contexto, las empresas necesitan lograr ventajas competitivas, es decir, características que las diferencien de sus competidores y les permitan colocarse en una posición relativa superior para competir. La forma de generar verdaderas ventajas competitivas sostenibles viene dada por las habilidades de las organizaciones para gestionar sus recursos en entornos cambiantes, es decir, por sus capacidades dinámicas. El dinamismo del entorno es la condición necesaria para el impulso de este tipo de capacidades puesto que, si el entorno en el que opera la empresa no está caracterizado por el acontecimiento de cambios, o si los cambios resultan fácilmente predecibles, no tiene sentido hablar de adaptación alguna a los mismos.

La dinámica de los mercados exige que las organizaciones desarrollen nuevas capacidades y las utilicen para el desarrollo de productos, servicios y procesos innovadores que les permitan obtener ventajas competitivas. Si la innovación es de proceso (introducción de un cambio significativo en la tecnología de producción de un bien o servicio) se logrará obtener una ventaja competitiva de liderazgo en costes y si es de producto o servicio (introducción en el mercado de nuevos o significativamente mejorados productos o servicios) se conseguirá una ventaja competitiva de diferenciación de producto o servicio.

\subsection{El enfoque de las capacidades dinámicas}

El enfoque de capacidades dinámicas surge del intento de Pisano (1994), Collins (1994) y Teece et al. (1997) por superar las limitaciones de la Teoría de Recursos y Capacidades. Dicha teoría define los beneficios de la empresa a partir únicamente de sus fortalezas y debilidades, entendiendo éstas como la existencia o la ausencia de recursos y capacidades que permitan lograr ventajas competitivas. Por tanto, esta teoría tiene un carácter estático y no considera el dinamismo del entorno causado por el avance tecnológico, los cambios regulatorios y de ciclo económico, el cambio competitivo y los cambios en las pautas de demanda.

Si el entorno en el que opera la empresa es de carácter relativamente estático, estable y cuyos cambios son predecibles, el valor estratégico de los recursos que configuran las capacidades competitivas de la empresa también se mantendrá estable, no erosionándose, por tanto, la ventaja competitiva con la que cuenta la misma. En este tipo de entornos no tendrá sentido hablar de capacidades dinámicas. Por el contrario, cuando los mercados son dinámicos o de "alta velocidad", el valor de los recursos y capacidades que sustentan la ventaja competitiva también varía, como se muestra en Garzón (2015) y debe tender a su mejora y ampliación, tal como se observa en el caso concreto que propone Collins (2021)

Dado que la Teoría de Recursos y Capacidades no es capaz de explicar cómo las empresas renuevan sus competencias para adaptarse al entorno cambiante y mantener sus ventajas competitivas, en las últimas décadas, se ha venido desarrollando por parte de la literatura especializada en dirección estratégica una nueva perspectiva que ha recibido el nombre de Capacidades Dinámicas (Teece, 2007). Por tanto, esta perspectiva surge para mejorar la capacidad explicativa de la Teoría de Recursos y Capacidades respecto al carácter sostenible de la ventaja competitiva en entornos de rápido cambio, al considerar la naturaleza evolutiva de los recursos y capacidades de la empresa con relación a los cambios en el entorno en el que opera la misma (Wang \& Ahmed, 2007). Las empresas que han logrado el éxito en tales ambientes competitivos son 
las que han demostrado capacidad de respuesta en el momento, y rápida y flexible innovación de producto (Teece et al., 1997).

\subsubsection{Capacidades dinámicas y reconfiguración de la ventaja competitiva}

El hecho de que el estudio del fenómeno de las capacidades dinámicas se haya abordado desde varias perspectivas teóricas o enfoques implica que, al modificarse la perspectiva desde la que se analiza el fenómeno de estudio, las conclusiones a las que se llega en cada análisis son diferentes, pero, como se observa a lo largo de este epígrafe, todas las perspectivas tienen en común la relación con la necesidad de replanteamiento con la ventaja competitiva para abordar el mercado.

Desde un enfoque contingente, las capacidades dinámicas se definen como capacidades que permiten responder a los cambios producidos en el entorno (Zajac et al. 2000); desde un enfoque de innovación, se refieren a la habilidad de la empresa para desarrollar nuevas soluciones (Teece \& Pisano, 1994); y desde la teoría de construcción de capacidades se conciben como capacidades que permiten modificar las capacidades o rutinas organizativas actuales de la empresa (Oliver \& Holzinger, 2008).

\subsubsection{Enfoque de innovación}

Abordando en primer lugar la corriente de innovación, ésta concibe las capacidades dinámicas en función de la capacidad que tiene la empresa para innovar, en sentido amplio, esto es, mediante el lanzamiento de nuevos productos o servicios, innovaciones de proceso o descubrimiento de nuevos mercados y modelos de negocio. Dentro de la evolución del concepto, se reconoce la necesidad de adaptación y generación de capacidades difíciles de imitar. Así, bajo esta corriente, las capacidades dinámicas parecen quedar definidas en función de su output (innovación). Este enfoque considera que la aplicación de las capacidades dinámicas tiene como resultado la innovación.

En cuanto a la evolución experimentada por este enfoque, la primera definición fue aportada en 1934 por Schumpeter, quien consideró la capacidad de innovación como la causante de la "destrucción creativa" que se refiere al proceso por el que la aparición de nuevos productos o servicios destruye otros ya existentes en el mercado, haciendo incluso desaparecer a empresas y modelos de negocios. Pero, según Schumpeter, este proceso depende de las características de la figura del emprendedor, quien será el responsable del cambio continuo y de la innovación. Sin embargo, hasta la aportación realizada por Teece y Pisano (1994) no se considera la existencia de una definición formal del concepto de capacidades dinámicas. Estos autores consideraron el dinamismo del entorno haciendo referencia a la innovación como herramienta para responder a las "circunstancias cambiantes del mercado" $y$, más adelante, describieron las capacidades dinámicas como aquéllas difíciles de imitar y que permiten a la empresa adaptarse a las necesidades cambiantes de los clientes y a los cambios tecnológicos que se producen en el mercado.

\subsubsection{Enfoque de construcción de las capacidades}

La corriente con mayor número de aportaciones es el enfoque de construcción de capacidades que entiende las capacidades dinámicas como las habilidades para integrar, construir y reconfigurar competencias o rutinas, a partir de la alteración y recombinación de los recursos con los que cuenta la empresa y la adquisición de nuevos recursos, lo cual tiene como resultado la generación de nuevas capacidades organizativas y la propia ventaja competitiva en respuesta al entorno cambiante. En este escenario, se desarrolla la búsqueda y administración de oportunidades y amenazas como elementos clave en las capacidades dinámicas, que permitan involucrar la generación de valor superior para los consumidores a partir del enfoque en la orientación y los intereses del mercado.

El primer autor de esta corriente fue Nelson, quien en 1991 definió el concepto de capacidades dinámicas introduciendo la evolución de las capacidades esenciales de la empresa dado que se encuentran en un contexto Schumpeteriano (evolutivo, de rápido cambio o de alta velocidad), por lo que las capacidades de la 
empresa también deben evolucionar y actualizarse al igual que su entorno. En 1997, Teece, Pisano y Shuen definieron las capacidades dinámicas como las habilidades de la empresa para reconfigurar sus competencias internas y externas en función de los cambios del entorno para lograr nuevas formas de obtener ventajas competitivas. Los autores cuyas aportaciones fueron posteriores a las de Teece, Pisano y Shuen también tuvieron en cuenta, a la hora de definir las capacidades dinámicas, la reconfiguración de los recursos para adaptarlos a las condiciones cambiantes del mercado y conseguir mantener la ventaja competitiva.

En 2007, Augier y Teece incorporaron a las anteriores definiciones el adjetivo de "inimitable" a la capacidad de la empresa para reconfigurar su base de activos. Por su parte, Oliver y Holzinger (2008) consideraron las capacidades dinámicas como las habilidades para desarrollar competencias internas que permitan satisfacer las necesidades del mercado.

\subsubsection{Enfoque contingente}

Existe una tercera corriente denominada enfoque contingente, en función de la cual las capacidades dinámicas se definen en términos de ajuste con las características del entorno. Según este enfoque, el ajuste respecto a las características de un entorno cambiante dependerá de la respuesta estratégica para adaptarse. Por lo tanto, los trabajos clasificados en esta corriente consideran que las capacidades dinámicas de la empresa responden a un esquema del tipo señales externas-interpretación-respuesta-evaluación. Las organizaciones deben mostrar una actitud proactiva a las señales que reciben de su entorno, interpretándolas y dándoles respuesta a las contingencias que puedan producirse y, por último, evaluar el grado de adaptación.

Eisenhardt y Martin (2000) definieron las capacidades dinámicas como los procesos estratégicos llevados a cabo por la empresa para obtener nuevas configuraciones de recursos cuando los mercados experimentan cambios. Se considera que las oportunidades del entorno que se aprovechen por las empresas pueden generar ventajas competitivas. Zajac et al. (2000) determinaron las capacidades dinámicas como las capacidades de la empresa para llevar a cabo el cambio necesario ante contingencias ambientales (externas) y organizativas (internas), lo que da lugar a un incremento del beneficio.

En 2001, Rindova y Kotha introdujeron el término "Continua Metamorfosis" para describir las transformaciones que experimentan las empresas para ajustar sus recursos a los cambios asociados a su entorno dinámico. Se concibieron las capacidades dinámicas como el origen de las ventajas competitivas sostenibles en entornos de continuo cambio. Para finalizar esta corriente, cabe mencionar la aportación realizada por Aragón-Correa y Sharma (2003), quienes consideraron que las capacidades dinámicas surgen como consecuencia de la aplicación de estrategias proactivas que tratan de anticiparse a los cambios y reducir la incertidumbre del entorno.

\subsubsection{Conclusiones de los tres enfoques}

Aunque las tres corrientes responden a esquemas distintos, no se puede considerar que las mismas sean excluyentes entre sí. En este sentido, tanto la corriente o enfoque de innovación, como la perspectiva contingente, parecen definir a las capacidades dinámicas en función de sus resultados o efectos, innovación y estado de adaptación, respectivamente. Sin embargo, aunque las definiciones que conforman cada enfoque difieren en cuanto a la forma en la que son enunciadas, pueden identificarse dos aspectos comunes en las mismas: capacidad de la empresa para mantenerse adaptada a entornos de rápido cambio. Ambos aspectos ponen de manifiesto la necesidad de tener en cuenta no sólo los factores externos (entorno) e internos (recursos y capacidades) de la organización, sino que también debe considerarse la evolución de ambos factores a lo largo del tiempo y la forma en la que las empresas logran el ajuste entre ellos mediante el "ajuste o encaje dinámico" entre los factores internos y los factores del contexto (Zajac et al., 2000; Rindova \& Kotha, 2001) para tratar de explicar la consecución de ventaja competitiva sostenible por parte de las empresas que operan en entornos de carácter dinámico en los que se producen cambios de carácter impredecible. 
Teece et al. (1997) afirmó que "las capacidades dinámicas reflejan la habilidad organizativa de lograr nuevas e innovadoras formas de ventaja competitiva". El desarrollo y la utilización de las capacidades dinámicas influyen en el nivel y alcance de la innovación de la empresa, lo que le permite mantenerse adaptada a un entorno cambiante. Las empresas con éxito en el mercado son aquellas que pueden demostrar la capacidad de respuesta oportuna y la innovación de productos de manera rápida y flexible, junto con la capacidad de gestión para coordinar eficazmente y redistribuir las competencias internas y externas. Por ello, este trabajo se centrará en el enfoque de innovación para articular la relación existente entre el desarrollo y el uso de las capacidades dinámicas de las organizaciones y sus esfuerzos para innovar, lo que supone un gran impacto sobre la gestión estratégica de la empresa, tal como señala Teece (2014), habida cuenta de que la empresa que no innova se ve avocada a tener que salir del mercado.

Para concluir, la definición de capacidades dinámicas propuesta en este trabajo es la siguiente: habilidades de la empresa para renovar y actualizar sus competencias en función de los cambios que vayan surgiendo en el entorno en el que operan, de forma que le permitan desarrollar nuevos procesos, productos o servicios con el fin de conseguir mantener o ampliar sus ventajas competitivas.

\subsubsection{Recursos y capacidades estratégicos relacionados con la capacidad de innovación}

Los recursos estratégicos más comúnmente relacionados con la capacidad de innovación son (Leonard \& Sensiper 1998; Oke et al. 2009): el capital humano, el liderazgo, la cultura y las estructuras y sistemas.

Respecto a las capacidades dinámicas necesarias para la innovación, según la literatura que analiza la gestión del conocimiento, las capacidades dinámicas asociadas a la innovación (Grant, 1996; Zahra \& George, 2002; Lavie, 2006) son: la creación de conocimiento, la absorción de conocimiento, la integración de conocimiento y la reconfiguración de conocimiento. Esto se relaciona con las capacidades generales de aprendizaje de la organización en las que la literatura al respecto está menos enfocada, tal como afirma Ipek (2019).

Además, tal como señala Zahra (2021), los investigadores apenas han estudiado la cuestión fundamental sobre cómo las empresas emprendedoras gestionan sus recursos para obtener una ventaja competitiva.

\section{METODOLOGÍA. MODELO PROPUESTO SOBRE LA RELACIÓN ENTRE LAS CAPACIDADES DINÁMICAS, LA INNOVACIÓN Y LA VENTAJA COMPETITIVA}

Metodológicamente se ha seguido el siguiente proceso. En primer lugar, a la luz de la literatura expuesta se ha elaborado un modelo de análisis para visualizar y, por tanto, poder gestionar, las capacidades dinámicas de la empresa en relación con innovación y la ventaja competitiva de la misma. De acuerdo con las variables que conforman cada uno de los constructos del modelo se han desarrollado las preguntas de una entrevista semi-estructurada (véase figura, Anexo), que se ha pasado a un miembro del equipo de altos directivos de cada empresa y, por último, teniendo en cuenta, no solo los resultados de la entrevista, sino también la información recabada de la observación directa (trabajo de alguno de los autores en las empresas observadas) y de los principales medios publicados por las empresas (páginas webs y memorias anuales), se ha procedido a un análisis de casos ejemplares en la provincia de Córdoba. Esto ha permitido proporcionar una herramienta útil desde el punto de vista estratégico.

El modelo construido (figura 1) requiere la siguiente interpretación: la movilización de los recursos que da lugar al desarrollo de capacidades y que forman parte del proceso de investigación y desarrollo empresarial culmina en resultados de innovación que llevan a la reconfiguración de la ventaja competitiva de la empresa. Este ciclo se retroalimenta ya que la nueva ventaja competitiva permite la adquisición de nuevos recursos y, por tanto, el desarrollo de nuevas capacidades que posibilitan nuevos procesos de innovación y, por consiguiente, nuevas maneras de competir. Dicho modelo se expresa a través de las variables e indicadores que se muestran en las tablas 2 a 4 a continuación, ya que en la literatura no se ha observado la existencia de una métrica o sistema de indicadores que evalúen la capacidad dinámica de innovación en las organizaciones, 
tal como indica Sánchez (2017). Pero, sí hay que poner de manifiesto la existencia de estudios específicos donde se observa que determinados recursos y capacidades desarrolladas en conjunto permiten a las empresas obtener competitividad, tal como se muestra en Acosta-Medina et al. (2018), otros modelos donde las capacidades dinámicas atienden a clasificaciones distintas de la planteada, como el de Garzón (2015) o casos muy concretos donde se analiza la influencia del entorno y de determinados recursos y capacidades empresariales sobre el resultado exportador, como en González-Ferriz (2021).

El entorno dinámico de las empresas les obliga a desarrollar capacidades dinámicas para adaptarse y responder a los requerimientos del contexto cambiante en el que se encuentran. Las capacidades dinámicas de la empresa están soportadas por la combinación de sus recursos estratégicos (capital humano, liderazgo, recursos físicos e infraestructuras, cultura organizativa, estructura y sistemas).

Por su parte, a partir de la creación, absorción, integración y reconfiguración del conocimiento, tanto interno como externo, las capacidades de las empresas pueden evolucionar rápidamente (capacidades dinámicas), lo cual les permiten desarrollar nuevos productos, servicios o métodos de producción para conseguir o mantener las ventajas competitivas. Por tanto, la innovación es el resultado de la aplicación de las capacidades dinámicas. En sentido similar se pronuncian Torres-Barreto y Antolinez (2017) que analizan cómo los intangibles de una empresa orientada hacia el emprendimiento influyen en su ventaja competitiva. Dicha innovación puede ser incremental si se introducen ciertos cambios en un producto existente para mejorarlo en algún aspecto, o radical cuando se incorpora al mercado un producto o servicio totalmente nuevo. Por otro lado, cuando la innovación es de proceso, es decir, hay un cambio significativo en el método de producción de un bien o servicio, dará lugar a una ventaja competitiva de liderazgo en costes debido a que se puede producir a menor coste como consecuencia de la nueva tecnología incorporada. Si la innovación es de producto o servicio, la ventaja competitiva que se puede lograr a partir de dicha innovación es la diferenciación del producto o servicio con respecto a los de la competencia, ya que la empresa proporciona algo único que valoran los clientes.

DINAMISMO DEL ENTORNO

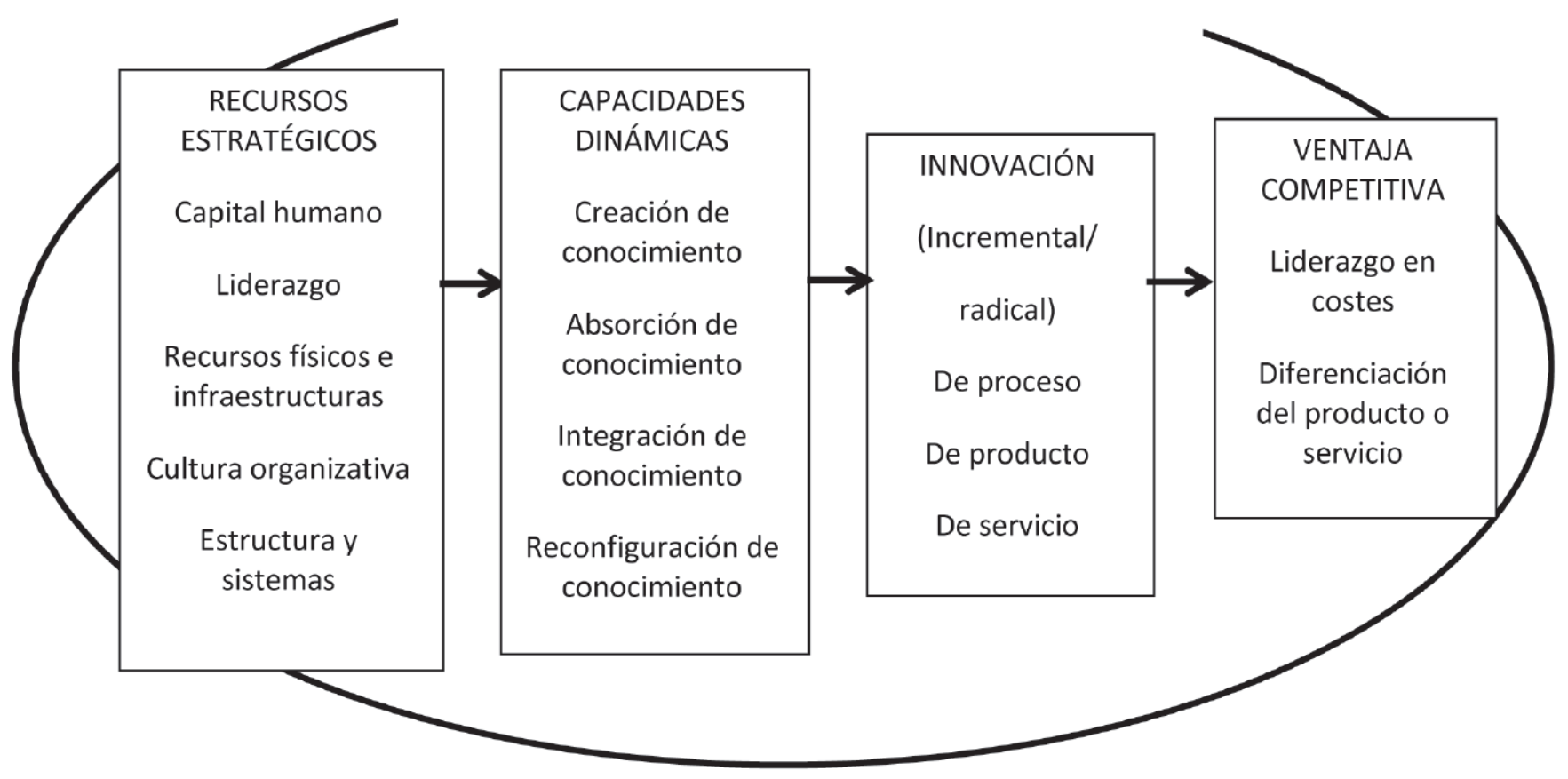

Figura 1. Modelo de reconfiguración de la ventaja competitiva. Fuente: Elaboración propia. 
Tabla 2. Variables e indicadores de los elementos del modelo relacionados con los recursos estratégicos.

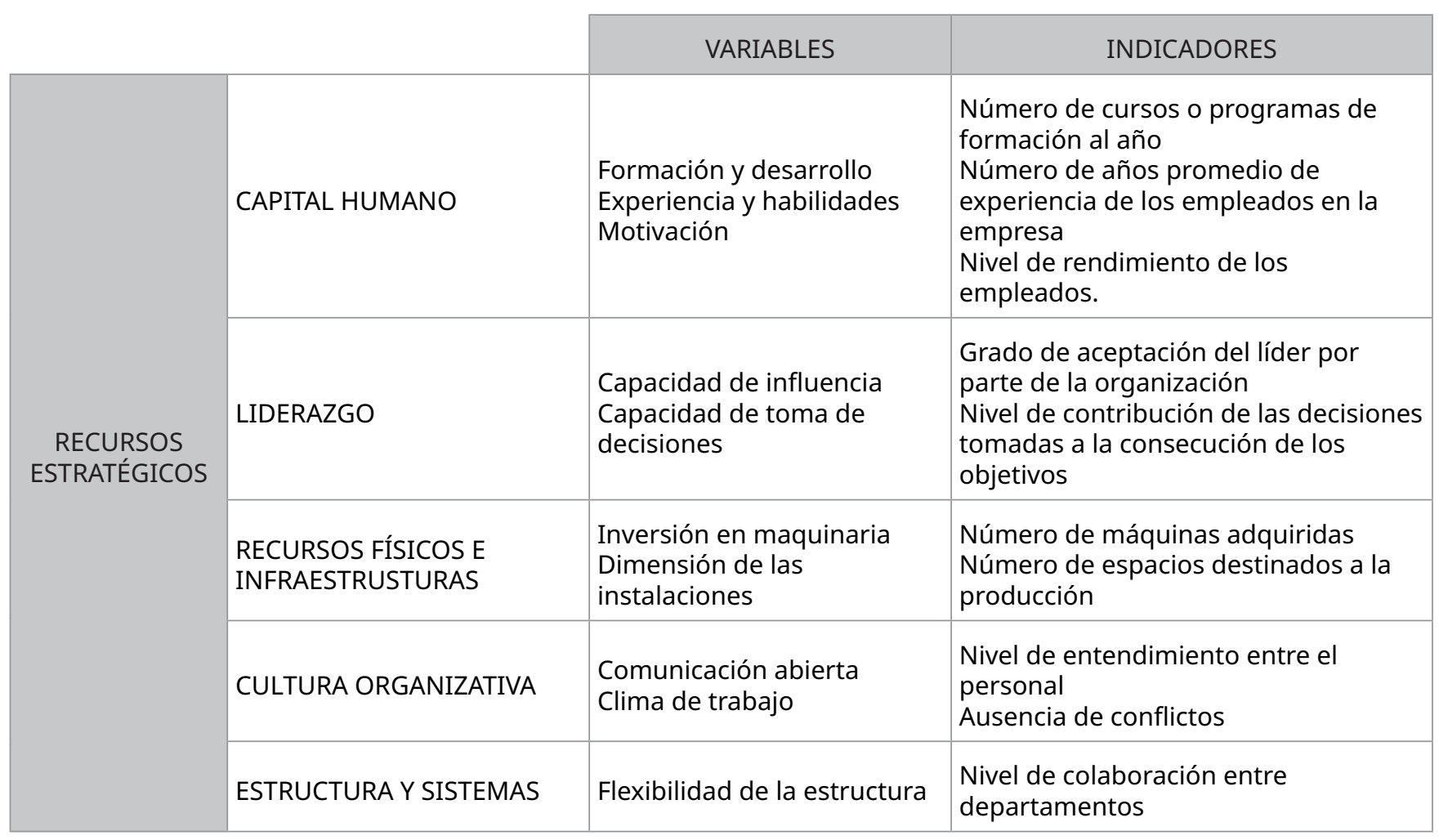

Fuente: Elaboración propia.

Tabla 3. Variables e indicadores de los elementos del modelo relacionados con las capacidades dinámicas.

\begin{tabular}{|c|c|c|c|}
\hline & & VARIABLES & INDICADORES \\
\hline \multirow{4}{*}{$\begin{array}{l}\text { CAPACIDADES } \\
\text { DINÁMICAS }\end{array}$} & $\begin{array}{l}\text { CREACIÓN DE } \\
\text { CONOCIMIENTO }\end{array}$ & $\begin{array}{l}\text { Solicitud de ofertas a } \\
\text { diferentes proveedores } \\
\text { Alianzas estratégicas } \\
\text { Recepción de información } \\
\text { de los clientes }\end{array}$ & $\begin{array}{l}\text { Número de ofertas solicitadas a } \\
\text { proveedores } \\
\text { Acuerdos de colaboración con otras } \\
\text { empresas del sector } \\
\text { Encuestas realizadas a los clientes }\end{array}$ \\
\hline & $\begin{array}{l}\text { ABSORCIÓN DE } \\
\text { CONOCIMIENTO }\end{array}$ & Inversión en I+D & $\begin{array}{l}\text { Porcentaje de beneficios destinado a } \\
\text { I+D }\end{array}$ \\
\hline & $\begin{array}{l}\text { INTEGRACIÓN DE } \\
\text { CONOCIMIENTO }\end{array}$ & $\begin{array}{l}\text { Intercambio de información } \\
\text { entre departamentos } \\
\text { Rutinas organizativas }\end{array}$ & $\begin{array}{l}\text { Reuniones periódicas entre los } \\
\text { miembros de los departamentos. } \\
\text { Número de tareas o actividades } \\
\text { determinadas por pautas de actuación } \\
\text { establecidas }\end{array}$ \\
\hline & $\begin{array}{l}\text { RECONFIGURACIÓN DE } \\
\text { CONOCIMIENTO }\end{array}$ & $\begin{array}{l}\text { Análisis del entorno } \\
\text { Búsqueda de oportunidades }\end{array}$ & $\begin{array}{l}\text { Estudios de mercado realizados } \\
\text { Número de oportunidades detectadas }\end{array}$ \\
\hline
\end{tabular}

Fuente: Elaboración propia. 
Tabla 4. Variables e indicadores de los elementos del modelo relacionados con la innovación y la ventaja competitiva.

\begin{tabular}{|c|c|c|c|}
\hline & & \\
\hline & & VARIABLES & INDICADORES \\
\hline \multirow[b]{2}{*}{ INNOVACIÓN } & DE PROCESO & $\begin{array}{l}\text { Introducción de nuevos } \\
\text { métodos de producción }\end{array}$ & Incorporación de nuevas tecnologías \\
\hline & DE PRODUCTO O SERVICIO & $\begin{array}{l}\text { Introducción en el mercado } \\
\text { de nuevos productos o } \\
\text { servicios } \\
\text { Modificaciones en los } \\
\text { productos o servicios } \\
\text { existentes }\end{array}$ & $\begin{array}{l}\text { Número de productos o servicios } \\
\text { introducidos en el mercado } \\
\text { Número de cambios realizados en los } \\
\text { productos o servicios }\end{array}$ \\
\hline \multirow{2}{*}{$\begin{array}{l}\text { VENTAJA } \\
\text { COMPETITIVA }\end{array}$} & LIDERAZGO EN COSTES & Reducción de costes & $\begin{array}{l}\text { Porcentaje de disminución de los } \\
\text { costes }\end{array}$ \\
\hline & $\begin{array}{l}\text { DIFERENCIACIÓN DEL } \\
\text { PRODUCTO O SERVICIO }\end{array}$ & $\begin{array}{l}\text { Mejora de la calidad del } \\
\text { producto o servicio }\end{array}$ & Grado de satisfacción del cliente \\
\hline
\end{tabular}

Fuente: Elaboración propia.

\section{RESULTADOS. ESTUDIO DE CASO}

\subsection{Selección y descripción de las empresas}

Para el estudio de casos se han seleccionado dos empresas representativas, una del ámbito público y otra del privado, cuyo sector de actividad es el de las Tecnologías de la Información y las Comunicaciones (TIC), que ha experimentado un importante progreso en los últimos años como consecuencia de los continuos cambios tecnológicos que se han producido y, por tanto, es un sector caracterizado por altas tasas de innovación.

Las razones anteriores, es decir, el ámbito y el sector al que pertenecen las empresas objeto de estudio, además de por su carácter representativo en la provincia de Córdoba y la facilidad de acceso a la información, justifican la elección de las empresas Eprinsa y ABBAS, que se describen a continuación.

De acuerdo a la página web de la primera empresa, Empresa Provincial de Informática S.A. (Eprinsa), ésta es una empresa pública creada por la Diputación de Córdoba en agosto de 1990 con objeto de dar asistencia informática integral, formación de personal y producción cartográfica a las Administraciones Locales de la provincia: los Ayuntamientos, Diputación, sus Organismos Autónomos, Empresas Públicas, Mancomunidades, Consorcios y otras Entidades Públicas Locales. Constituye un instrumento de coordinación y dinamización que coopera en la modernización de la gestión local de Córdoba nuestra provincia, mediante el diseño e implantación de proyectos I+D. Para ello, cuenta con los medios técnicos y humanos más avanzados en el tratamiento de la información y las telecomunicaciones.

Desde Eprinsa se impulsa el Plan Informático Provincial, que comprende un programa de ayuda a la inversión municipal en infraestructura, mediante la cesión de software de base, licencias de uso de aplicaciones, dotaciones de equipamientos de hardware, gasto de comunicaciones, etc.

Las actuaciones dentro de este marco de cooperación se realizan en las siguientes áreas:

- Administración, instalaciones y consultoría de sistemas operativos, bases de datos y comunicaciones.

- Soporte a usuarios, hot-line (línea telefónica de servicio ininterrumpido que se ofrece a los usuarios para llamadas de urgencia y problemas técnicos) y gestión de incidencias informáticas.

- Desarrollo, mantenimiento, soporte y formación de aplicaciones de gestión local y otras licencias de software.

Además, se disponen de otros servicios comerciales:

- Soporte de hardware y software aparte de los servicios de cooperación: averías, microinformática, redes locales, etc. 
- Todo lo relacionado con el acceso, diseño, mantenimiento, soporte y publicación en internet, correo electrónico.

- Trabajos de impresión corporativa, subproductos cartográficos y desarrollo de aplicaciones multimedia a medida.

Aparte, afirman seguir creando nuevos servicios: gestión de contenidos, intercambios de información, unificación de comunicaciones, soporte remoto, outsourcing, imagen corporativa, etc.

Debido a lo anterior, Eprinsa ha tenido varios reconocimientos públicos al trabajo y avances tecnológicos logrados, que van más allá de la provincia, recibiendo por ello varios galardones de prestigio, tal como figura en su propia web.

La otra empresa que se va a analizar es Abbas Servicios de Informática y Telecomunicaciones, S.L., una empresa privada constituida en octubre de 2014 con objeto de prestar servicios avanzados de informática y telecomunicaciones para empresas y operadores: servicios de ingeniería de sistemas, sistemas de almacenamiento, copias de seguridad y de aplicaciones de gestión empresarial, servicios de housing de servidores y hosting (alojamiento de portales web),transmisión de datos (red corporativa) y acceso a internet, y desarrollo de aplicaciones verticales (softwares diseñados para fines específicos) para el sector de las telecomunicaciones $u$ otros sectores donde la demanda no esté cubierta. Sus clientes objetivos son las empresas de 50 o más empleados, o aquellas empresas que cuenten con una plataforma informática de complejidad equivalente.

\subsection{Análisis de los casos}

En cuanto a las innovaciones de servicio, Eprinsa implantó en 2012 el acceso electrónico de los ciudadanos a los servicios públicos de la provincia de Córdoba para que pudieran realizar diferentes trámites municipales a través de la sede electrónica de los Ayuntamientos. Este proyecto fue cofinanciado por la Diputación de Córdoba y el Fondo Europeo de Desarrollo Regional. Además de facilitar las relaciones entre las Administraciones y los ciudadanos, está innovación fue llevada a cabo para acelerar a la puesta en marcha de una Administración electrónica en Córdoba, según obligaba la Ley 11/2007, de 22 de junio, de acceso electrónico de los ciudadanos a los servicios públicos, que reconocía el derecho de los ciudadanos a relacionarse con las Administraciones Públicas por medios electrónicos.

Por el contrario, la innovación de servicio de ABBAS estaba destinada a sus clientes empresas, a fin de permitirles seguir disponiendo del servicio de transmisión de datos gracias a una línea de respaldo que cubriera la avería de la línea principal. Esta innovación fue íntegramente financiada por la propia empresa, por lo que, a diferencia de Eprinsa, no contó con la ayuda de otras instituciones u organismos públicos para la financiación del proyecto.

Ambas empresas también han realizado innovaciones de proceso. La de Eprinsa ha consistido en la sustitución de la infraestructura de sus sistemas centrales mediante la adquisición de servidores de almacenamiento en red para ampliar la capacidad de almacenamiento de información de sus clientes. Antes de la puesta en marcha de la innovación, se realizaron estudios de las necesidades y capacidades de la empresa, así como de las necesidades de sus clientes. En cambio, la innovación de proceso de ABBAS se basó en la atención técnica a clientes empresariales prestada directamente por ingenieros de red o de sistemas, dado que se detectó que los problemas técnicos que presentaban los clientes se resolvían de forma más eficaz si eran atendidos por ingenieros en lugar de por teleoperadores.

Las innovaciones de ambas empresas (tabla 5), tanto las de servicios como las de proceso, tienen un carácter incremental porque han supuesto mejoras en sus prestaciones. No han sido radicales porque, en el caso de Eprinsa, la innovación de servicio ha consistido en la introducción del acceso electrónico de los ciudadanos a las sedes electrónicas de los Ayuntamientos, y la de proceso en ampliar la capacidad de almacenamiento de la empresa para prestar un mejor servicio. ABBAS únicamente ha incorporado a la línea principal de transmisión de datos otra línea de respaldo por lo que, no se ha introducido un servicio totalmente nuevo. Y su innovación de proceso ha permitido una mejora en la prestación de los servicios porque los 
problemas técnicos de los clientes son atendidos por personal cualificado que cuenta con los conocimientos necesarios para comprenderlos y resolverlos.

Tabla 5. Resumen y comparación de las innovaciones de ambas empresas.

\begin{tabular}{|c|c|c|}
\hline & EPRINSA & ABBAS \\
\hline INNOVACIÓN DE SERVICIO & $\begin{array}{l}\text { Implantación del Acceso Electrónico de } \\
\text { los Ciudadanos a los Servicios Públicos } \\
\text { de la provincia de Córdoba }\end{array}$ & $\begin{array}{l}\text { Líneas de respaldo para que no se } \\
\text { pierda el servicio cuando las líneas } \\
\text { principales sufran alguna avería. }\end{array}$ \\
\hline INNOVACIÓN DE PROCESO & $\begin{array}{l}\text { Adquisición de servidores de } \\
\text { almacenamiento en red para ampliar } \\
\text { la capacidad de almacenamiento de } \\
\text { información de sus clientes. }\end{array}$ & $\begin{array}{l}\text { Atención técnica a clientes } \\
\text { empresariales prestada directamente } \\
\text { por ingenieros de red o de sistemas. }\end{array}$ \\
\hline $\begin{array}{l}\text { TIPO DE INNOVACIÓN SEGÚN SU } \\
\text { GRADO DE NOVEDAD }\end{array}$ & Incrementales & Incrementales \\
\hline
\end{tabular}

Fuente: Elaboración propia.

Analizando los recursos estratégicos de ambas empresas (tabla 6) podemos observar que Eprinsa ha llevado a cabo acciones formativas anuales para que su capital humano se actualice y profundice respecto a nuevas técnicas y conocimientos útiles para el desarrollo de las innovaciones efectuadas. Por el contrario, ABBAS ha considerado que no son necesarios los cursos de formación para sus empleados, ya que éstos ya cuentan con los conocimientos necesarios para aplicarlos a las innovaciones.

Con relación a las decisiones tomada por el líder, ha sido muy importante la decisión de la Diputación de Córdoba de financiar el servicio innovador y, la del gerente de Eprinsa para la puesta en marcha de las innovaciones, por lo que podemos identificar la existencia de un liderazgo de tipo transformacional, ya que Eprinsa depende de las decisiones que tome la Diputación y su gerente. Sin embargo, en ABBAS existe un liderazgo transaccional dado que las decisiones son tomadas de forma conjunta, contando además con consultores externos.

Para el desarrollo de las innovaciones, en Eprinsa se ha producido una transformación de las infraestructuras para responder a las necesidades de almacenamiento de datos de los clientes. En cambio, ABBAS ya disponía de unas infraestructuras adaptadas a sus servicios tecnológicos, por lo que no ha sido necesario transformar sus recursos físicos.

Comparando la cultura organizativa de ambas empresas, tal y como se puede observar en la tabla 6, los valores que comparten los miembros de cada organización son diferentes. Pero tanto en la empresa pública como en la privada, se han visto reforzados tras las innovaciones.

El último recurso analizado es la estructura y sistemas, que en el caso de Eprinsa, para la introducción de las innovaciones, se ha creado una comisión compuesta por miembros de todos los departamentos. Por el contrario, en ABBAS no se ha producido una variación en su estructura pero, se ha fortalecido el nivel de colaboración entre los departamentos como consecuencia de la innovación.

Tanto en la empresa pública como en la privada se han llevado a cabo prácticas que se pueden asociar con sus capacidades dinámicas (tabla 7).

Para la creación de conocimiento, Eprinsa elabora, por orden de la Diputación, un expediente de contratación, antes de la adquisición de los sistemas de almacenamiento, en el que se analizan de forma exhaustiva las distintas ofertas de los proveedores. Sin embargo, en ABBAS únicamente se solicita ofertas a distintos proveedores para compras de importe elevado. Dado que Eprinsa es una empresa pública, mantiene una encomienda de gestión con la Diputación de Córdoba, es decir, un acuerdo por el cual la Diputación encomienda a Eprinsa la ejecución del proyecto de Implantación del Acceso Electrónico. En cambio, ABBAS mantiene acuerdos de colaboración con otras empresas del sector y se han creado equipos técnicos conjuntos formados por ingenieros de ambas empresas, para dar solución a problemas concretos. Otra forma de creación de conocimiento de Eprinsa es la realización de encuestas anuales a los clientes para medir su nivel de 
satisfacción con los servicios prestados. ABBAS no realiza este tipo de encuestas pero, mide la satisfacción de sus clientes a través de hechos como que el cliente no se dé de baja en sus servicios y que los recomiende a otras empresas.

Tabla 6. Resumen y comparación de los recursos de ambas empresas.

\begin{tabular}{|c|c|c|}
\hline & EPRINSA & ABBAS \\
\hline $\begin{array}{l}\text { CONOCIMIENTOS Y FORMACIÓN DEL } \\
\text { CAPITAL HUMANO }\end{array}$ & $\begin{array}{l}\text { Acciones formativas anuales para } \\
\text { la actualización y profundización de } \\
\text { nuevas técnicas y conocimientos. }\end{array}$ & $\begin{array}{l}\text { Aplicación de los conocimientos de la } \\
\text { plantilla, la cual cuenta con titulación } \\
\text { superior en ingeniería. }\end{array}$ \\
\hline DECISIONES TOMADAS POR EL LÍDER & $\begin{array}{l}\text { Decisión de la Diputación para } \\
\text { financiar la innovación de servicio y } \\
\text { del gerente de Eprinsa para la puesta } \\
\text { en marcha de las innovaciones. }\end{array}$ & $\begin{array}{l}\text { Dado el carácter técnico y experto de } \\
\text { la plantilla, las decisiones se toman } \\
\text { de forma conjunta, contando además } \\
\text { con consultores externos. }\end{array}$ \\
\hline $\begin{array}{l}\text { RECURSOS FÍSCOS E } \\
\text { INFRAESTRUCTURAS }\end{array}$ & $\begin{array}{l}\text { Transformación de infraestructuras } \\
\text { para responder a necesidades de } \\
\text { capacidad. }\end{array}$ & $\begin{array}{l}\text { Disponibilidad de infraestructuras } \\
\text { adaptadas a los servicios } \\
\text { tecnológicos. }\end{array}$ \\
\hline $\begin{array}{l}\text { CULTURA ORGANIZATIVA (valores } \\
\text { aceptados por la organización) }\end{array}$ & $\begin{array}{l}\text { Transparencia, trabajo en equipo } \\
\text { y comunicación abierta entre el } \\
\text { personal. }\end{array}$ & $\begin{array}{l}\text { Orientación al cliente, integración y } \\
\text { excelencia profesional. }\end{array}$ \\
\hline $\begin{array}{l}\text { ESTRUCTURA Y SISTEMAS (nivel de } \\
\text { colaboración entre departamentos) }\end{array}$ & $\begin{array}{l}\text { Creación de una Comisión } \\
\text { compuesta por miembros de todos } \\
\text { los departamentos y de grupos de } \\
\text { trabajo multidepartamentales. }\end{array}$ & $\begin{array}{l}\text { Fortalecimiento del nivel de } \\
\text { colaboración entre departamentos. }\end{array}$ \\
\hline
\end{tabular}

Fuente: Elaboración propia.

La práctica asociada a la absorción de conocimiento llevada a cabo por ambas empresas es la inversión en I+D, sin embargo, es diferente en cada empresa, ya que en Eprinsa varía en función de su beneficio; y en ABBAS se destina un porcentaje fijo que representa el $10 \%$ del beneficio.

Para integrar el conocimiento, en las dos empresas analizadas se realizan reuniones entre los miembros de los distintos departamentos, pero la frecuencia es distinta en cada una de ellas, dado que en Eprinsa se organizan semanalmente y en ABBAS de forma continuada para tratar temas de importancia, como pueden ser los problemas técnicos de los clientes.

Por último, la capacidad dinámica de reconfiguración de conocimiento hace referencia a la generación de nuevas formas de creación de valor. Para ello, ambas empresas realizaron una búsqueda de oportunidades que permitieron el desarrollo de las innovaciones. En el caso de Eprinsa se descubrió la necesidad de simplificar los trámites con las Administraciones públicas y dar respuesta a la ley que reconoce el derecho de acceso electrónico de los ciudadanos a los servicios públicos. En cambio, ABBAS identificó la oportunidad de crear una línea de respaldo a la línea principal de transmisión de datos, observando las carencias de los servicios prestados por la competencia.

Por último, comentar (tabla 8) que, tanto Eprinsa como ABBAS coinciden en que uno de sus recursos que más ha evolucionado tras el desarrollo de sus innovaciones, ha sido el capital humano debido al incremento de sus capacidades, que en la empresa pública se ha producido mediante las acciones formativas, y en la empresa privada como consecuencia de la aplicación de los conocimientos de su plantilla. En cambio, en Eprinsa se han desarrollado más los recursos físicos por la modernización de sus infraestructuras, y en ABBAS ha evolucionado más la cultura organizativa debido a sus valores de orientación al cliente y excelencia profesional, los cuales han sido esenciales para identificar las necesidades de los clientes y ofrecer un servicio de respaldo a las líneas principales de transmisión de datos.

En cuanto a las capacidades dinámicas, ambas empresas han desarrollado la creación de conocimiento como consecuencia de las tres prácticas llevadas a cabo, pero en el caso de Eprinsa ha evolucionado más la reconfiguración de conocimiento por los estudios de las necesidades y capacidades de la empresa, así 
como de las necesidades de sus clientes para la introducción de sus innovaciones. Sin embargo, en ABBAS, la absorción de conocimiento ha progresado de manera más acusada, ya que todos los años se destina un porcentaje fijo de sus beneficios a la inversión en I+D, y en Eprinsa este porcentaje es variable dependiendo de sus beneficios.

Tabla 7. Resumen y comparación de las capacidades dinámicas de ambas empresas.

\begin{tabular}{|c|l|l|}
\cline { 2 - 3 } \multicolumn{1}{c|}{} & \multicolumn{1}{|c|}{ EPRINSA } & \multicolumn{1}{c|}{ ABBAS } \\
\hline CREACIÓN DE CONOCIMIENTO & $\begin{array}{l}\text { Elaboración de expedientes de } \\
\text { contratación. } \\
\text { Acuerdo de colaboración con la } \\
\text { Diputación de Córdoba. } \\
\text { Encuestas anuales a clientes. }\end{array}$ & $\begin{array}{l}\text { Solicitud de ofertas a proveedores } \\
\text { para compras sustanciales. } \\
\text { Acuerdos de colaboración con otras } \\
\text { empresas del sector. } \\
\text { Utilización de factores para medir la } \\
\text { satisfacción del cliente. }\end{array}$ \\
\hline ABSORCIÓN DE CONOCIMIENTO & $\begin{array}{l}\text { Inversión en I+D varía en función del } \\
\text { beneficio. }\end{array}$ & $\begin{array}{l}\text { Inversión en I+D de un porcentaje } \\
\text { superior al 10\% del beneficio. }\end{array}$ \\
\hline INTEGRACIÓN DE CONOCIMIENTO & $\begin{array}{l}\text { Reuniones semanales para revisar } \\
\text { el avance de los objetivos de la } \\
\text { empresa y tratar temas generales } \\
\text { yécnicos que afecten a más de un } \\
\text { departamento. }\end{array}$ & $\begin{array}{l}\text { Reuniones de forma continuada para } \\
\text { temas de importancia. }\end{array}$ \\
\hline CONOCIMIENTO & $\begin{array}{l}\text { Oportunidad detectada en la } \\
\text { innovación de servicio fue la } \\
\text { necesidad de crear una administración } \\
\text { electrónica que redujera la duración } \\
\text { de las gestiones y trámites. }\end{array}$ & $\begin{array}{l}\text { Identificación de oportunidades } \\
\text { analizando las carencias de los } \\
\text { servicios prestados tradicionalmente } \\
\text { por la competencia. }\end{array}$ \\
\hline
\end{tabular}

Fuente: Elaboración propia.

Las innovaciones desarrolladas por ambas empresas han contribuido a la reconfiguración de sus ventajas competitivas. La innovación de servicio de Eprinsa ha afianzado el carácter integral, innovador y exclusivo de sus servicios prestados a organismos públicos, y la innovación de proceso ha permitido incrementar la calidad de estos servicios debido a la adquisición de servidores que han ampliado la capacidad de almacenamiento de los datos de sus clientes. En cambio, en la empresa privada ABBAS, tanto su innovación de servicio como la de proceso han mejorado la calidad de sus servicios, tanto en fiabilidad porque los clientes cuentan con la garantía de una línea de respaldo para la transmisión de datos, como en funcionalidades por las características de sus servicios adaptados a las necesidades de sus clientes.

Tabla 8. Resumen y comparación de la evolución de los recursos y capacidades dinámicas como elementos que de reconfiguración de la ventaja competitiva de ambas empresas.

\begin{tabular}{|c|l|l|}
\cline { 2 - 3 } & \multicolumn{1}{c|}{ EPRINSA } & \multicolumn{1}{c|}{ ABBAS } \\
\hline EVOLUCIÓN DE LOS RECURSOS & $\begin{array}{l}\text { Incremento de las capacidades del } \\
\text { capital humano. } \\
\text { Modernización de las infraestructuras. }\end{array}$ & $\begin{array}{l}\text { Incremento de las capacidades del } \\
\text { capital humano. } \\
\text { Refuerzo de la cultura organizativa. }\end{array}$ \\
\hline $\begin{array}{c}\text { EVOLUCIÓN DE LAS CAPACIDADES } \\
\text { DINÁMICAS }\end{array}$ & $\begin{array}{l}\text { Creación de conocimiento. } \\
\text { Reconfiguración de conocimiento. }\end{array}$ & $\begin{array}{l}\text { Creación de conocimiento. } \\
\text { Absorción de conocimiento. }\end{array}$ \\
\hline VENTAJA COMPETITIVA & $\begin{array}{l}\text { Prestación de un servicio de carácter } \\
\text { integral, innovador y exclusivo a } \\
\text { organismos públicos. }\end{array}$ & $\begin{array}{l}\text { Calidad de los servicios prestados, } \\
\text { tanto en fiabilidad como en } \\
\text { funcionalidades. }\end{array}$ \\
\hline
\end{tabular}

Fuente: Elaboración propia. 


\section{DISCUSIÓN Y CONCLUSIONES}

En conclusión, en ambas empresas (una pública y otra privada), se ha puesto de manifiesto como su ventaja competitiva se reconfigura de acuerdo a sus capacidades dinámicas, atendiendo a las directrices que se exponen a continuación, la cuales son susceptibles de extrapolación, con carácter general, a otras empresas de diferentes sectores o países.

En lo que respecta a la gestión de su conocimiento, especialmente en su etapa de captación, hay que tener en cuenta que el comportamiento colaborativo, las interacciones sociales y las distintas formas de relación vertical, como modos de captación del conocimiento, incrementan el desarrollo de capacidades (Vanpoucke et al., 2014; He et al., 2018 y Mamédio, 2019)

Si se atiende a la formación de los empleados, que resulta un pilar fundamental, esta formación se completa con reuniones de forma periódica que favorecen la integración del conocimiento, lo que resulta esencial ya que, tal como señala Sanluke et al. (2019), para dar soluciones al mercado, además del conocimiento externo e interno, se necesita la capacidad de integración del mismo.

Respecto al refuerzo de la cultura organizativa de la empresa, donde destaca la potenciación del espíritu colaborativo necesario para el desarrollo de innovaciones, hay que apuntar que constituye un soporte básico de la estrategia de la empresa (Bueno \& Morcillo, 2019), lo que se relaciona con la idea puesta de manifiesto en Teece (2019) que explica cómo la estrategia empresarial junto a las capacidades dinámicas determina una ventaja competitiva sostenible en un entorno global.

Si se atiende al proceso progresivo que supone la innovación (incremental), este análisis ha permitido reafirmar la idea de Piening y Salge (2015) que propugnan que las actividades específicas de innovación respaldan las capacidades dinámicas y sus interrelaciones en términos de efectos complementarios o sustitutivos.

Sin embargo, se observa en la empresa privada en comparación con la pública una orientación más estrecha hacia el cliente, que lleva a centrar la ventaja competitiva en la calidad alimentada por estructuras poco jerarquizadas donde priman las ideas del grupo y/o asesoramiento de empresas especializadas, partiendo de estructuras tecnológicas muy punteras. En el caso de la empresa pública, las decisiones orientadas las clientes pueden verse dotadas de un cierto cariz político. Por otro lado, las inversiones realizadas para el desarrollo de las mismas dependen de presupuestos públicos y los procesos suelen ser más lentos al tener que cumplir toda la serie de trámites burocráticos marcados por las Administraciones.

En el caso de la empresa pública, sobre todo si es de baja tecnología, tiene especial importancia el hecho de que la innovación organizativa produce un efecto directo y positivo en el rendimiento de la empresa (Ryeowon et al., 2019).

La integración de conocimientos se canaliza a través del entramado de comunicaciones que se producen en la empresa, tanto de tipo formal como informal, especialmente en los grupos y reuniones de trabajo. Se vislumbra como estas comunicaciones suelen fluir más ágilmente en el ámbito privado que en el público.

La contribución principal de este trabajo se relaciona con el aporte de una herramienta estratégica relacionada con la gestión de las capacidades dinámicas que forman parte del proceso de desarrollo de una ventaja competitiva innovadora en la empresa. Ambos constructos se retroalimentan y permiten la evolución de la entidad. Además, se ponen de manifiesto diferentes maneras de actuar en la práctica, tanto del sector público como privado.

Para investigaciones futuras se propone hacer extensible el estudio a una muestra amplia de empresas, además de, tal como se apuntó en la introducción de este trabajo, cuantificar el tiempo de reacción de un tipo y otro de empresas. Sería también interesante determinar el porcentaje de $I+D+i$ dedicado en cada proceso y tipo de empresa.

\section{Agradecimientos}

Sean nuestros agradecimientos para las empresas colaboradoras en este trabajo, que han hecho posible su desarrollo. 


\section{Declaración responsable y conflicto de intereses}

Las autoras declaran que no existe ningún conflicto de interés con relación a la publicación de este artículo, que ha sido fruto del trabajo colaborativo y equilibrado entre todas ellas.

\section{REFERENCIAS}

Acosta-Medina, J., Plata-Gómez, K.R., Puentes-Garzón D.E. \& Torres-Barreto, M. L. (2018). Influence of resources and capabilities in finance performance and business competitiveness: a literature review. I+D Revista de Investigaciones, 13(1), 125-134. https://doi.org/10.33304/revinv.v13n1-2019013

Ambrosini, V., Bowman, C. \& Collier, N. (2009). Dynamic Capabilities: An Exploration of How Firms Renew their Resource Base. British Journal of Management, 20, Special Issue, S9-S24. https://doi.org/10.1111/j.1467-8551.2008.00610.x

Aragón-Correa, J.A. \& Sharma, S. (2003). A Contingent Resource-Based View of Proactive Corporate Environmental Strategy. Academy of Management Review, 28(1), 71-88. https://doi.org/10.5465/amr.2003.8925233

Augier, M. \& Teece, D.J. (2007). Dynamic Capabilities and Multinational Enterprise: Penrosean Insights and Omissions. Management International Review, 47(2), 175-192. https://doi.org/10.1007/s11575-007-0010-8

Bueno E. \& Morcillo P. (2019, 25-27 septiembre). Un proceso estratégico para la empresa sostenible. Cultura, Ventaja Adaptativa y Estrategia [Comunicación]. XX Congreso Internacional AECA. Asociación Española de Contabilidad y Administración de Empresas, Málaga.

Collins, D.J. (1994). Research Note: How Valuable are Organizational Capabilities? Strategic Management Journal, 15, Winter Special Issue, 143-152. https://doi.org/10.1002/smj.4250150910

Collins, C. J. (2021). Expanding the resource based view model of strategic human resource management. The International Journal of Human Resource Management, 32(2), 331-358. https://doi.org/10.1080/09585192.2019.1711442

Eisenhardt, K.M. \& Martin, J.A. (2000). Dynamic capabilities. What are they? Strategic Management Journal, 21(10/11), 1105-1121. https://doi.org/10.1002/1097-0266(200010/11)21:10/11<1105::AID-SMJ133>3.0.CO;2-E

Garzón, M. A. (2015). Modelo de Capacidades Dinámicas. Dimensión Empresarial, 13 (1), 111-131. https://doi.org/10.15665/ rde.v13i1.341

González-Ferriz, F. (2021). Análisis de los factores determinantes del resultado exportador en las empresas españolas del sector calzado. Revista de Estudios Andaluces, 42, 138-157. https://doi.org/10.12795/rea.2021.i42.07

Grant, R.M. (1996). Prospering in dynamically-competitive environments: Organizational capability as knowledge integration. Organization Science, 7(4), 375-387. https://doi.org/10.1287/orsc.7.4.375

He, X., Yi, Y. \& Wei, Z. (2018). New product development capabilities in China: the moderating role of TMT cooperative behavior. Asian Business Management, 18(2), 73-97. https://doi.org/10.1057/s41291-018-00055-X

Ipek, I. (2019). Organizational learning in exporting: a biblimetric analysis and critical review of the empirical research. International Business Review, 28(3), 544-559. https://doi.org/10.1016/j.ibusrev.2018.11.010

Kale, D. (2010). The Distinctive Patterns of Dynamic Learning and Inter-firm Differences in the Indian Pharmaceutical Industry. British Journal of Management, 21(1), 223-238. https://doi.org/10.1111/j.1467-8551.2009.00651.x

Lavie, D. (2006). Capability Reconfiguration: An Analysis of Incumbent Responses to Technological Change. Academy of Management Review, 31(1), 153-174. https://doi.org/10.5465/amr.2006.19379629

Leonard, D. \& Sensiper, S. (1998). The role of tacit knowledge in group innovation. California Management Review, 40(3), 112-125. https://doi.org/10.2307/41165946

Mamédio, D., Rocha,C., Szczepanik, D. \& Kato, H. (2019). Strategic alliances and dynamic capabilities: a systemic review. Journal of Strategy Management, 12(1), 83-102. https://doi.org/10.1108/JSMA-08-2018-0089

Mikalef, P., Boura, M. \& Lekakos, G. (2019). Big Data Analytics Capabilities and Innovation: The Mediating Role of Dynamic Capabilities and Moderating Effect of the Environment. British Journal of Management, 30(2), 272-298. https://doi. org/10.1111/1467-8551.12343

Miranda, J. (2015). El Modelo de las Capacidades Dinamicas en las Organizaciones. Investigación Administrativa, $44,116$. https://doi.org/10.35426/IAv44n116.05

Nelson, R.R. (1991). Why Do Firms Differ, and How Does it Matter? Strategic Management Journal, 12, 61-74. https://doi. org/10.1002/smj.4250121006 
Oke, A., Munshi, N. \& Walumbwa, F. (2009). The Influence of Leadership on Innovation Processes and Activities. Organizational Dynamics, 38(1), 64-72. https://doi.org/10.1016/j.orgdyn.2008.10.005

Oliver, C. \& Holzinger, I. (2008). The Effectiveness of Strategic Political Management: A Dynamic Capabilities Framework. Academy of Management Review, 33(2), 496-520. https://doi.org/10.5465/amr.2008.31193538

Peng, G. \& Beamish, P. (2014). MNC Subsidiary Size and Expatriate Control: Resource-Dependence and Learning Perspectives. Journal of World Business, 49(1), 51-62. https://doi.org/10.1016/j.jwb.2012.11.001

Piening, E. P. \& Salge, T. O. (2015). Understanding the antecedent, contingencies, and performances implications of process innovation: a dynamic capabilities perspective. The Journal of Product Innovation Management, 32(1), 80-97. https://doi.org/10.1111/jpim.12225

Pisano, G. (1994). Knowledge, Integration, and the Locus of Learning: An Empirical Analysis of Process Development. Strategic Management Journal, 15, winter special issue, 85-100. https://doi.org/10.1002/smj.4250150907

Ryeowon, L., Jong-Ho, L. \& Garret T. C. (2019). Synergy effects of innovation on performance. Journal of Business Research, 99, 507-515. https://doi.org/10.1016/j.jbusres.2017.08.032

Rindova, V.P. \& Kotha, S. (2001). Continuous 'Morphing': Competing Through Dynamic Capabilities, Form and Function. Academy of Management Journal, 44(6), 1263-1280. https://doi.org/10.2307/3069400

Saluke, S., Weerawardena, J. \& McColl-Kennedy, J.R. (2019). The central role of knowledge integration capability in service innovation-based competitive strategy. Industrial Marketing Management, 76, 144-156. https://doi.org/10.1016/j. indmarman.2018.07.004

Sánchez, D. (2017). Cómo medir la capacidad dinámica de innovación en las organizaciones. Universidad Simón Bolívar, Venezuela. https://doi.org/10.17081/bonga/2089.c4

Sidhu, J.S., Commandeur H.R. \& Volberda, H.W. (2007). The Multifaceted Nature of Exploration and Exploitation: Value of Supply, Demand, and Spatial Search for Innovation. Organization Science, 18(1), 20-38. https://doi.org/10.1287/ orsc. 1060.0212

Suárez, F. \& Oliva, R. (2005). Environmental Change and Organizational Transformation. Industrial and Corporate Change, 14(6), 1017-1041. https://doi.org/10.1093/icc/dth078

Teece, D. J. (2019). A dynamic capabilities-based entrepreneurial theory of the multinational enterprise. Journal of International Business Studies, 45. 8-37. https://doi.org/10.1057/jibs.2013.54

Teece, D. J. (2014). The foundations of enterprise performance: dynamic and ordinary capabilities in an (economic) theory of firms. Academy of Management Perspective, 28 (4), 328-352. https://doi.org/10.5465/amp.2013.0116

Teece, D.J. (2007). Explicating dynamic capabilities. The nature and microfoundations of (sustainable) enterprise performance. Strategic Management Journal, 28 (13), 1319-1350. https://doi.org/10.1002/smj.640

Teece, D.J. \& Pisano, G. (1994). The Dynamic capabilities of firms: an Introduction, Industrial and Corporate Change, 3(3), 537-556. https://doi.org/10.1093/icc/3.3.537-a

Teece,D.J., Pisano, G. \& Shuen, A. (1997). Dynamic capabilities and strategic management. Strategic Management Journal, 18(7), 509-533. https://doi.org/10.1002/(SICI)1097-0266(199708)18:7<509::AID-SMJ882>3.0.CO;2-Z

Torres-Barreto, M. L. \& Antolinez, D. F. (2017). Exploring the boosting potential of intellectual resources and capabilities on firm's competitiveness. Espacios, 38(31). Retrieved from http://www.revistaespacios.com/a17v38n31/ a17v38n31p35.pdf.

Vanpoucke. E, Vereecke, A. \& Wetzels, M. (2014). Developing supplier integration capabilities for sustainable competitive advantage: a dynamic capabilities approach. Journal of Operations Management, 32(7-8), 446-461. https://doi. org/10.1016/j.jom.2014.09.004

Wang, C.L. \& Ahmed, P.K. (2007). Dynamic capabilities: a review and research Agenda. International Journal of Management Reviews, 9(1), 31-51. https://doi.org/10.1111/j.1468-2370.2007.00201.x

Zahra, S. A. \& George, G. (2002). Absorptive capacity: a review, reconceptualization, and extension. Academy of Management Review, 27(2), 185-203. https://doi.org/10.5465/amr.2002.6587995

Zahra, S. A. (2021). The Resource-Based View, Resourcefulness, and Resource Management in Startup Firms: A Proposed Research Agenda. Journal of Management, 01492063211018505. https://doi.org/10.1177/01492063211018505

Zajac, E.J., Kraats, M.S. \& Bresser, R.F.K. (2000). Modeling the dynamics of strategic fit: a normative approach to strategic change. Strategic Management Journal, 21(4), 429-453. https://doi.org/10.1002/(SICI)1097-0266(200004)21:4<429::A ID-SMJ81>3.0.CO;2-\# 
ANEXO

\section{Entrevista semi-estructurada}

1. ¿Cuáles han sido las dos innovaciones más importantes llevadas a cabo en los últimos años por su empresa? Por favor, señale una innovación de producto o servicio ${ }^{1}$, y otra de proceso ${ }^{2}$.

2. ¿Cómo se detectaron las oportunidades en el mercado que llevaron a introducir las innovaciones anteriores? ¿Qué métodos o técnicas se han utilizado para identificarlas?

3. ¿Las innovaciones realizadas han sido incrementales ${ }^{3}$ o radicales ${ }^{4}$ ?

4. Describa cómo han contribuido al desarrollo de estas innovaciones los siguientes recursos estratégicos:

- Los conocimientos y la formación del capital humano.

- Las decisiones tomadas por el líder de la organización.

- Los recursos físicos e infraestructuras (maquinaria, instalaciones, tecnología).

- La cultura organizativa (los valores generalmente aceptados por los miembros de la organización, la comunicación y el clima de trabajo existente).

- La estructura y sistemas (el nivel de colaboración entre los diferentes departamentos).

5. ¿Antes de adquirir la maquinaria o las materias primas, servicios, etc. correspondientes a las innovaciones indicadas en la pregunta 1, la empresa solicitó ofertas a los diferentes proveedores?

6. ¿La empresa mantiene acuerdos de colaboración con otras empresas o instituciones que favorecieron la introducción de estas innovaciones (las de la pregunta 1)? En caso afirmativo, explique de qué manera.

7. ¿Se realizan encuestas a los clientes para recoger información sobre sus necesidades y medir su grado de satisfacción con el producto o servicio ofrecido? En caso afirmativo, indique cómo esta información favoreció la introducción y consolidación de las innovaciones especificadas en la pregunta 1.

8. ¿La empresa destina un porcentaje de sus beneficios anuales a la inversión en I+D+i?

9. ¿Se organizan reuniones periódicas para intercambiar información entre los miembros de los diferentes departamentos?, ¿cuáles son los temas tratados en dichas reuniones?, ¿cómo favoreció la información recogida en estas reuniones a la introducción de las innovaciones especificadas (en la pregunta 1)?

10. ¿Cuál es su ventaja competitiva5? ¿Cree que ha cambiado/evolucionado a raíz de la introducción de las innovaciones (de la pregunta 1)?

11. Del mismo modo, después de la introducción de estas innovaciones, ¿considera que han evolucionado los siguientes recursos y capacidades de la organización? (señale con una X lo que considere oportuno).

1 Introducción en el mercado de nuevos (o significativamente mejorados) productos o servicios. Incluye alteraciones significativas en las especificaciones técnicas, en los componentes, en los materiales, la incorporación de software o en otras características funcionales.

2 Implementación de nuevos (o significativamente mejorados) procesos de fabricación, logística o distribución. Por ejemplo, redefinir los procesos productivos puede servir para aumentar el valor del producto final gracias a un menor coste de fabricación, un menor tiempo de respuesta o una mayor calidad.

3 La innovación incremental tiene lugar cuando se introducen ciertos cambios en algún proceso, producto o servicio existente para mejorarlo en algún aspecto.

4 La innovación radical se refiere a la introducción en el mercado de un producto o servicio totalmente nuevo o a la incorporación de un nuevo proceso.

5 La ventaja competitiva hace referencia a cualquier característica de la empresa que la diferencia de otras, colocándola en una posición relativa superior para competir y permitiéndole obtener un rendimiento superior a las otras en su actuación competitiva. El origen de la ventaja competitiva puede estar en numerosas características de la actividad de la empresa, pero cualquiera de ellas conduce a una de las dos ventajas competitivas básicas: liderazgo en costes o diferenciación del producto o servicio. 


\begin{tabular}{|c|c|c|c|c|c|}
\hline Recursos y Capacidades & Mucho & Bastante & Un poco & $\begin{array}{c}\text { Muy } \\
\text { ligeramente }\end{array}$ & $\begin{array}{l}\text { No han } \\
\text { evolucionado }\end{array}$ \\
\hline \multicolumn{6}{|l|}{$\begin{array}{l}\text { Incremento de las capacida- } \\
\text { des del capital humano }\end{array}$} \\
\hline \multicolumn{6}{|l|}{ Impulso del Liderazgo } \\
\hline \multicolumn{6}{|l|}{$\begin{array}{l}\text { Incremento de recursos } \\
\text { físicos y modernización de las } \\
\text { infraestructuras }\end{array}$} \\
\hline \multicolumn{6}{|l|}{$\begin{array}{l}\text { Refuerzo de la cultura orga- } \\
\text { nizativa (creencias, valores } \\
\text { compartidos) }\end{array}$} \\
\hline \multicolumn{6}{|l|}{$\begin{array}{l}\text { Flexibilidad de laestructura y } \\
\text { sistemas (nivel de colabora- } \\
\text { ción entre los departamentos) }\end{array}$} \\
\hline \multicolumn{6}{|l|}{ Creación de conocimiento ${ }^{6}$} \\
\hline \multicolumn{6}{|l|}{ Absorción de conocimiento ${ }^{7}$} \\
\hline \multicolumn{6}{|l|}{ Integración de conocimiento 8} \\
\hline $\begin{array}{l}\text { Reconfiguración de conoci- } \\
\text { miento }^{9}\end{array}$ & & & & & \\
\hline
\end{tabular}

6 La creación de conocimiento se refiere al proceso que incrementa y hace disponible el conocimiento creado por los individuos por medio de la creación de alianzas estratégicas, relaciones cercanas con el cliente, etc.

7 La capacidad de absorción se define como la habilidad y motivación de los empleados para obtener conocimiento externo y utilizarlo para el desarrollo de la capacidad de innovación. En definitiva, se trata de la habilidad para reconocer el valor de la nueva información, asimilarla y aplicarla a fines comerciales.

8 El concepto de integración ha sido definido como el conjunto de procedimientos inter-organizacionales y entre unidades funcionales orientados a la interacción y la colaboración, es decir, aquellos procedimientos que buscan el intercambio de información y la colaboración entre departamentos o entre organizaciones.

9 La reconfiguración de conocimiento se define como el proceso de generación de nuevas alternativas de configuración de capacidades, actividades organizativas y formas de creación de valor ante los cambios que se produzcan en el mercado. Para ello, es necesaria la búsqueda de oportunidades y la identificación dichos cambios. 